\title{
Comparison of Outcomes of Early Versus Delayed Laparoscopic Cholecystectomy in Acute Calcular Cholecystitis
}

\author{
Mohammed Mohammed El-Kordy, Al Sayed Basiony Aboulyazid, Ahmed Fakhry Ahmed Mahmoud* \\ Department of General Surgery, Faculty of Medicine Al-Azhar University, Cairo, Egypt \\ *Correspondence author: Ahmed Fakhry Ahmed Mahmoud, Mobile: (+20) 01028018712, \\ E-mail: ahmedfakhry41@gmail.com
}

\section{ABSTRACT}

Background: acute cholecystitis is the most common cause of hospitalization for gastrointestinal disease. Although cholecystectomy is the definitive management, the timing of surgery in relation to the first episode of acute cholecystitis remains an area of considerable practice variation.

Objective: The aim of this study was to evaluate the results of early laparoscopic cholecystectomy versus conservative management and delayed elective cholecystectomy in acute calcular cholecystitis.

Patients and Methods: the present study is a prospective randomized study done during the period from November 2018 to June 2019. The study included 40 patients with acute calcular cholecystitis presented to Al-Azhar University Surgical department. They had been classified randomly by taking every two patients; one patient to the group A, the other patient to group B, and each group consisted of 20 patients.

Results: the mean operative time in the early group was more than the mean operative time in the delayed group. The conversion rate to open cholecystectomy in the early group was less than the conversion rate in the delayed group. The mean total hospital stay in the early group was less than the mean total hospital stay in the delayed group. Finally the overall complications in the early group were less than complications occurred in the delayed group. Conclusion: early laparoscopic cholecystectomy for patients with acute cholecystitis has both medical and socioeconomic benefits and it is the preferred approach in comparison to delayed approach.

Keywords: Laparoscopic Cholecystectomy, Calcular Cholecystitis.

\section{INTRODUCTION}

Acute cholecystitis is one of the most significant acute diseases inthe WesternWorld, and may be associated with only mild pain andnausea or become a severe, life-threatening illness due to complications. Acute cholecystitis is mainly caused by gall stones, while cholestasis ismainly associated with super infection with bacteria, in general species of enterobacteria, enterococci, bacteroides and anaerobic streptococci ${ }^{(\mathbf{1})}$.

Following the first episode of acute cholecystitis, the annual risk of gallstone-related complications can increase up to 30\%; and laparoscopic cholecystectomy (LC) is the first-line definitive surgical management ${ }^{(2)}$.

The management of patients with gall stone diseases has been revolutionized during the last decade with the introduction and evolution of laparoscopic cholecystectomy. The laparoscopic technique for cholecystectomy was first performed by Philippe Mouret in Lyon, France in 1987 and was developed and spread among general surgeons all over the world. Laparoscopic cholecystectomy has become the gold standard in the treatment of symptomatic cholelithiasis and has revolutionized minimally invasive procedures ${ }^{(3)}$.

The risk of developing second and subsequent episodes of acute cholecystitis is higher than the risk of suffering an initial episode.Laparoscopic cholecystectomy is therefore usually recommended, butwhether this should be performed immediately or after giving antibiotic treatment to allow the acute condition to subside is controversial $^{(4)}$.
The main complication of acute cholecystitis is recurrent biliary colic and cholestasis. The latter may lead to ascending cholangitis, andwhile this can be managed with antibiotics, other complications cannot be cured conservatively such as gangrenous changes, gall bladder perforation and biliary leakage, and acute necrotic gallstone pancreatitis. Liver abscesses and underlying incidental carcinoma have also beenreported in some cases ${ }^{(5)}$. Early LC is usually performed within a week of the onset ofsymptoms, when local inflammation obscures optimal view and raisesconcerns about increased intraoperative complications. Alternatively, LCcan be delayed (usually for 6 weeks of symptom onset), when acuteinflammation is resolved. Nevertheless, recent meta-analyses suggestedthat early LC (within 1 week of symptom onset) is safe and feasible ${ }^{(6)}$. Aim of the work:

The aim of this study was to evaluate the results of early laparoscopic cholecystectomy versus conservative management and delayed elective cholecystectomy in acute calcular cholecystitis.

\section{PATIENTS AND METHODS}

The present study is a prospective randomized study done during the period from November 2018 to June 2019. The study included 40 patients with acute calcular cholecystitis presented to Al-Azhar University Surgical department, El Hussein hospital. They had been classified randomly by taking every two patients; one patient to the group A, the other patient to group B, and each group consisted of 20 patients. 
Group (A) underwent laparoscopic cholecystectomy in the first seventy-two hours (3 days) from the onset of symptoms.

Group (B) underwent delayed interval laparoscopic cholecystectomy after six to eight weeks of conservative treatment.

Diagnosis of acute cholecystitis was based upon right hypochondrial pain which persists for more than 24 hours, right hypochondrial tenderness, fever, leucocytosis and ultrasonic evidence of acute calcular cholecystitis, all cases should have gall stones either single or multiple, other ultrasonic evidence of acute calcular cholecystitis including, thickened wall of the gallbladder, pericholecystic fluid collection and distended gall bladder.

Ethical approval and written informed consent: An approval of the study was obtained from Al-Azhar University Academic and Ethical Committee. Every patient signed an informed written consent for acceptance of the operation.

Clinical assessment:

1. History taking.

2. Examination: General and local examination.

3. Investigations.

a) Laboratory:

General pre-operative investigations were done for all the patients including:

Full blood count, prothrombin time and INR.

Liver function tests: bilirubin (total and direct) and

alkaline phosphatase, albumin and liver enzymes

(AST, ALT).

Kidney function tests and electrolytes: serum urea, serum creatinine, sodium and potassium.

b) Cardio-vascular and respiratory investigations: All patients had ECG, Chest X-ray; while some had Echocardiogram if they suffered from cardiac troubles, and respiratory function test and arterial blood gases if they had respiratory troubles.

c) Imaging: All patients had pre-operative pelviabdominal ultrasound commenting on the gall bladder wall thickness, the number of the stones, their size and site and presence of pericholecystic fluid collection along with other intra-abdominal and pelvic organs pathology.

All patients received the following line of treatment on admission:

- Nothing per mouth (N.P.O), which continued for the early group (A) till the time of the operation, while nothing per mouth for the delayed group (B) continued till the attack subsided and symptoms improved (no fever, tachycardia or leucocytosis).

- Intra venous fluids.

- Broad spectrum third generation cephalosporins antibiotic injection 1gram every 12 hours up to 24 hours postoperative in group $\mathrm{A}$ and up to 5 days in group B.
- All patients in both groups received narcotic analgesic in the form of Pethidine 50mg every 12 hours with antispasmodic injection for 24 hours then sodium diclofenac (Voltaren) $75 \mathrm{mg}$ was given when needed.

- Nasogastric tube (NGT) has been used for those patients who were complaining of vomiting.

For group (A) laparoscopic cholecystectomy was performed within 72 hours on the first available list. For group (B) laparoscopic cholecystectomy performed after six to eight weeks of conservative treatment.

Operative Details:

1- Preparation and Positioning:

- General anaesthesia was used. All the patients were intubated with a cuffed endotracheal tube and ventilated mechanically.

- Ryle tube was inserted orally to decompress the stomach and lower limb elastic stocking to guard against deep venous thrombosis.

- Single dose of a third generation cephalosporin was administered with the induction.

- In this study, the standard technique for lap.

Cholecystectomy was used, with the patients were placed in the standard supine position with the surgeon and camera man standing at the patient's left, the second assistant on the right and the monitor at the shoulder level of the patient. The patient was generally placed in a reverse

Trendelenburg position and rotated right side up.

2- Insertion of ports and creation of pneumoperitoneum:

- Insertion of the umbilical port using open Hasson technique and $\mathrm{Co}_{2}$ insufflation for creation of pneumoperitoneum was done and the laparoscope was placed at the umbilicus to perform diagnostic laparoscopy. Then the other three ports were inserted under vision (port 2 was inserted in the epigarstrium to the right of the midline, port 3 was inserted in the mid clavicular line and port 4 was placed in the anterior axillary line).

- Dissection of adhesions that may be present between the omentum and the gall bladder and the liver and anterior abdominal wall (Figure 1).

- The distended gall bladder was aspirated first via aspiration needle and the fundus was raised with $5 \mathrm{~mm}$ forceps.

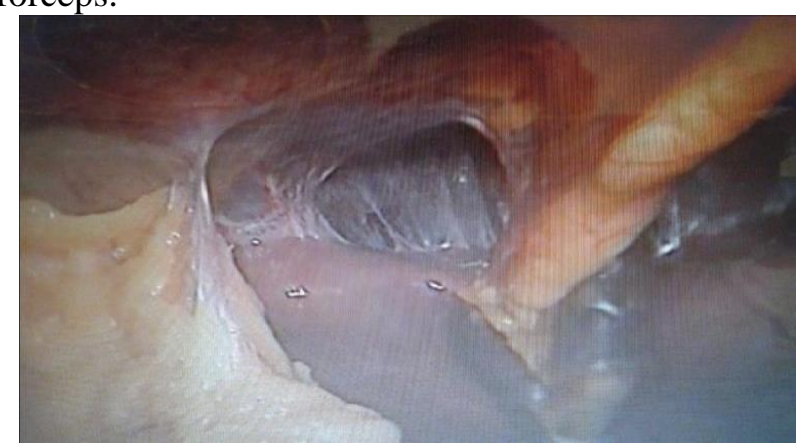

Figure (1): Adhesions was found between the liver and omentum and anterior abdominal wall. 
3- Dissection of the cystic pedicle

- The anterior and posterior peritoneum overlying Calot's triangle was incised, usually with the Lshaped hook with creation of windows between the cystic artery and duct (Figure 2).

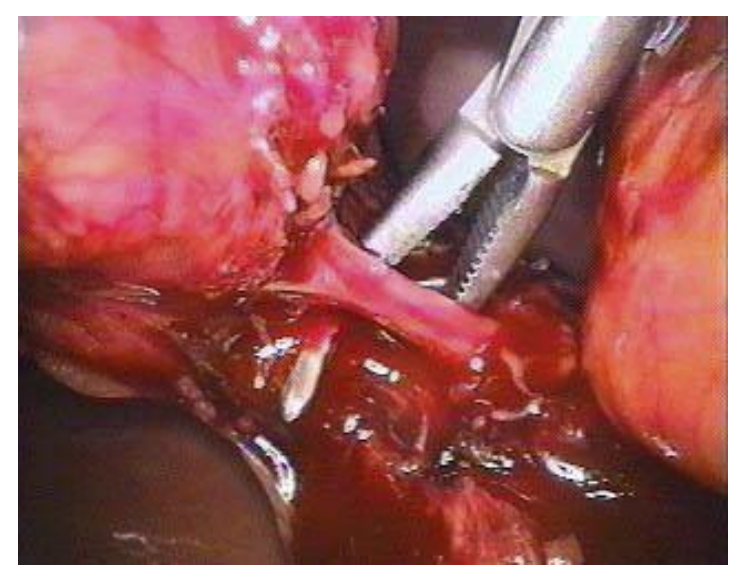

Figure (2): Dissection of cystic artery

- The cystic artery and duct were clipped after obtaining the critical view of safety (Figure 3).

- Mass division or clipping of any large clump of tissue or duct structure was avoided.

- Care was taken for looped right hepatic artery which can be easily mistaken for the cystic artery.

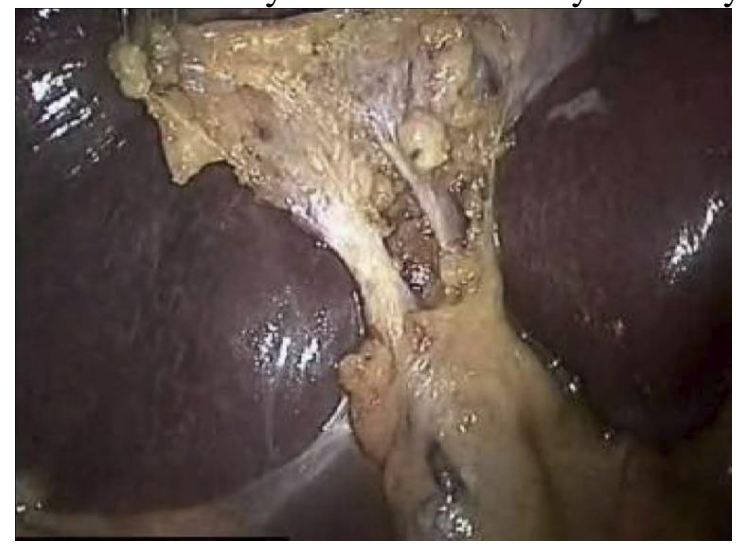

Figure (3): Critical view of safety

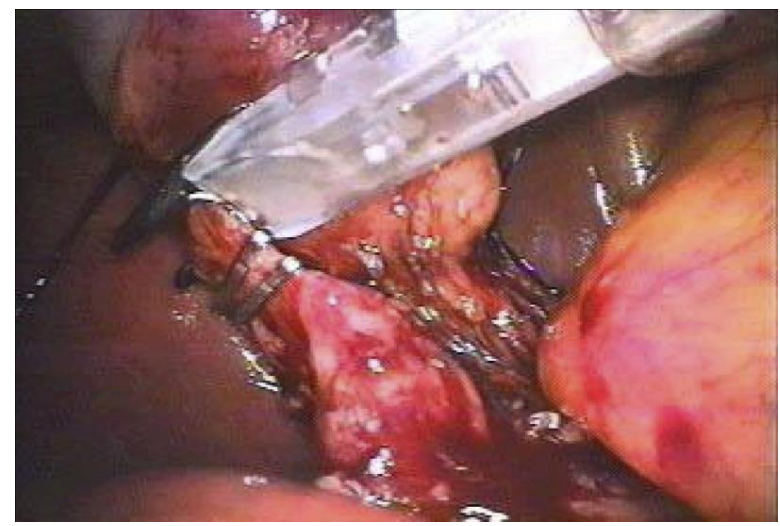

Figure (4): Clipping of cystic duct

4- Dissection of the gallbladder from its liver bed:

- Electrocautery dissection of the gallbladder completed the cholecystectomy. The dissection was started behind the Hartmann's pouch (Figure 5).
- Gentle traction was applied to the gallbladder moving it from side to side so that the loose areolar tissue can be demonstrated (Figure 6).

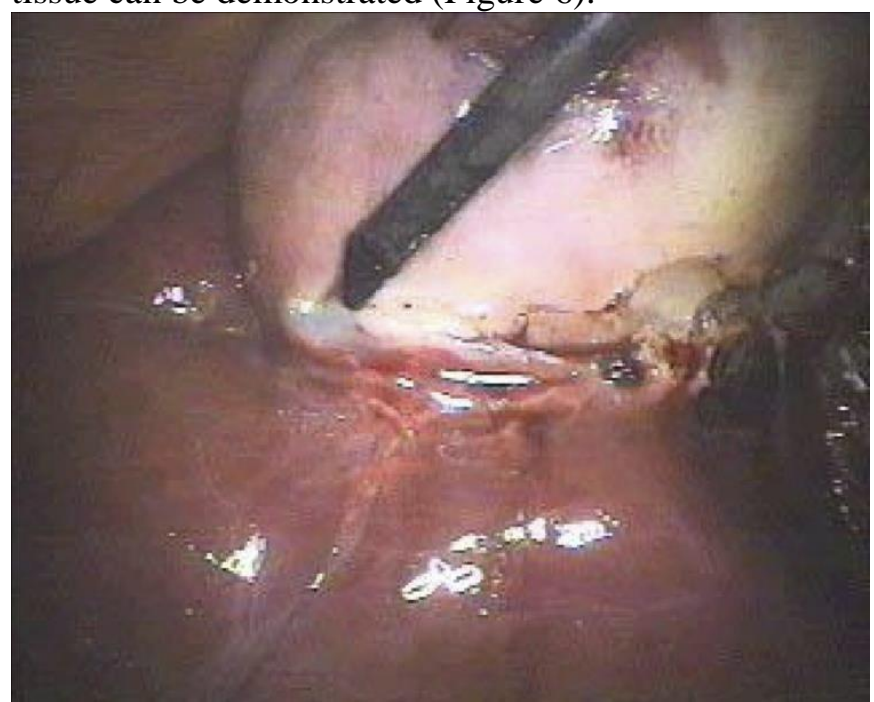

Figure (5): Hook electro-cautery used to dissect the gallbladder off the liver bed

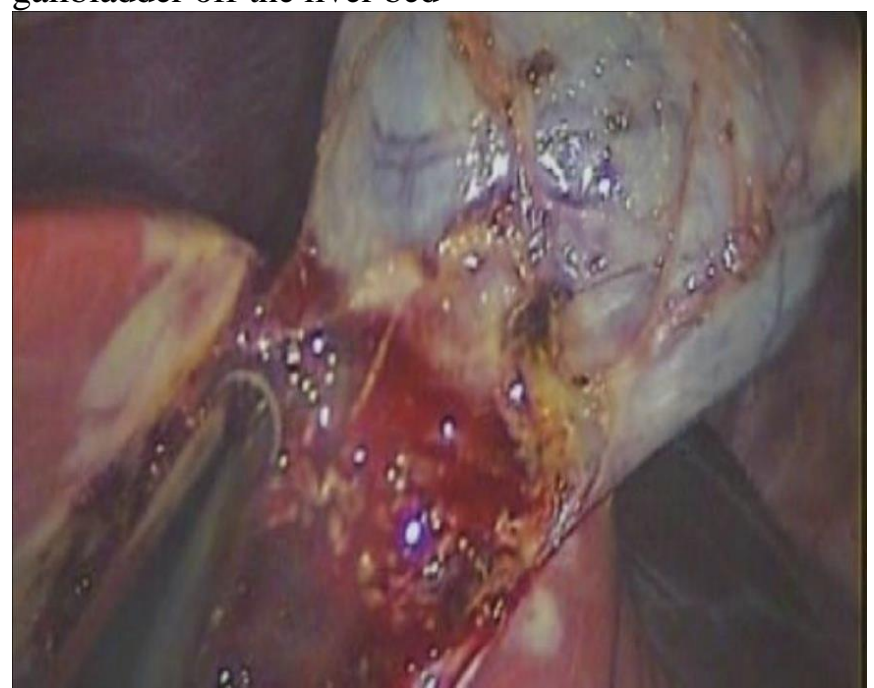

Figure (6): Removal of the gall bladder from its bed.

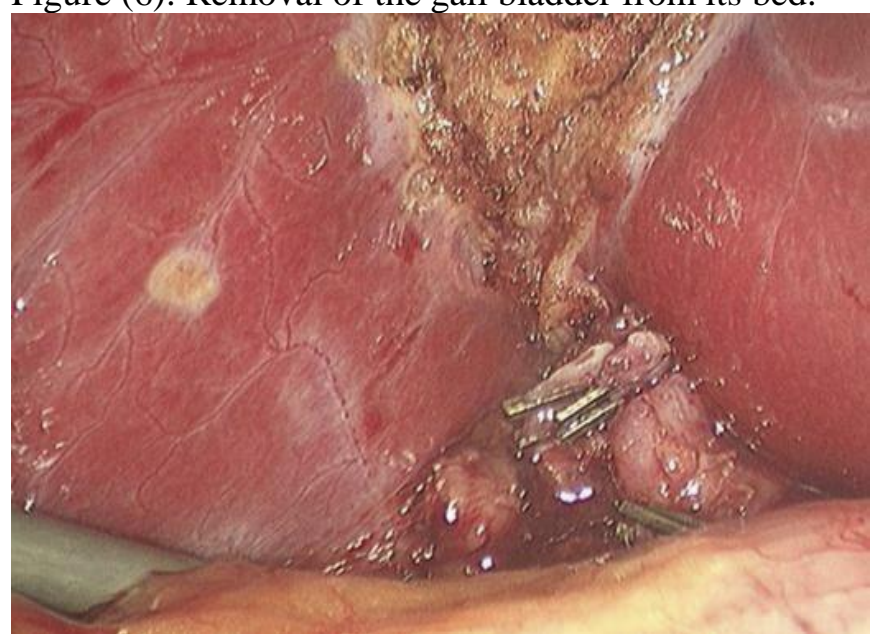

Figure (7): Clean liver bed with clipped cystic duct and cystic artery.

5- Extraction of the gallbladder:

- The gallbladder was extracted through the epigastric port (Figure 8). Fascial closure was attempted only at the umbilical cannula site. 
- During extraction of the distended gall bladder widening of the epigastric port could be done to facilitate its extraction and to avoid spillage of its contents.

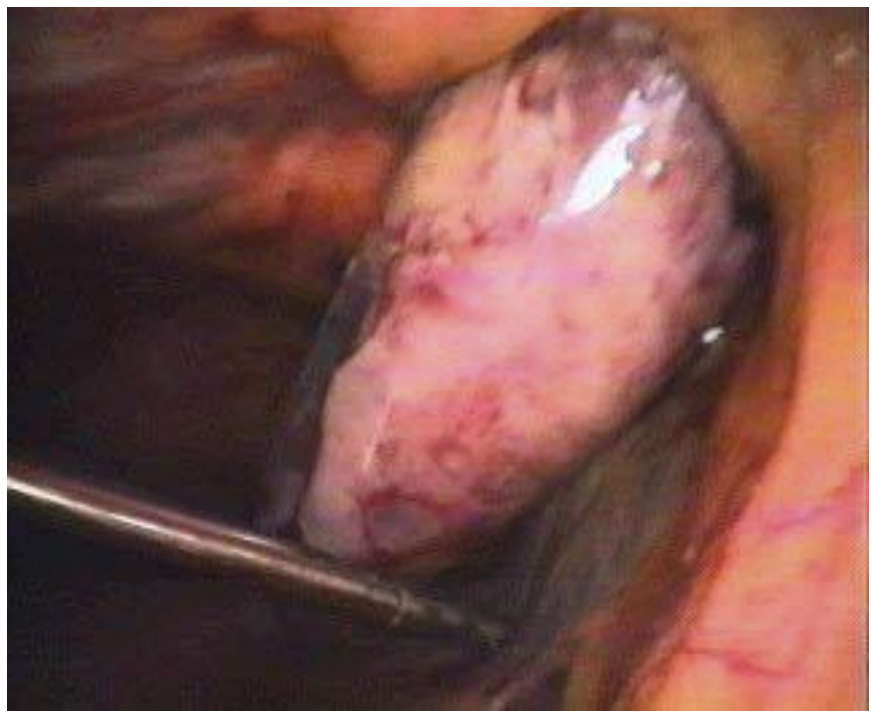

Figure (8): Extraction of the gallbladder.

In this study, when conversion to open cholecystectomy was necessary (due to difficult dissection at Calot's triangle) a right subcostal incision was performed, the area was isolated with packs, the neck of the gallbladder was grasped with sponge holding forceps, the cystic artery was divided between ligatures, The cystic duct was then ligated and divided, the gallbladder was dissected from its liver bed, then was removed, haemostasis assured and the abdominal wall was closed in layers.

Post-operative workup and follow up

1) All patients received intra-venous fluids for only 12 hours followed by oral fluids and soft diet.

2) All Patients received intravenous third generation cephalosporin for 1 day postoperatively every 12 hours.

3) The patients were discharged after removal of the drain and when they were open bowel and tolerating oral intake.

4) Follow up was done in outpatient clinic for one month postoperative. Abdominal ultrasound was done for selected cases.

\section{Statistical analysis}

Recorded data were analyzed using the statistical package for social sciences, version 20.0 (SPSS Inc., Chicago, Illinois, USA). Quantitative data were expressed as mean \pm standard deviation (SD). Qualitative data were expressed as frequency and percentage.

\section{The following tests were done:}

- Independent-samples t-test of significance was used when comparing between two means.

- Chi-square $\left(\mathrm{x}^{2}\right)$ test of significance was used in order to compare proportions between two qualitative parameters.
- The confidence interval was set to $95 \%$ and the margin of error accepted was set to 5\%. The pvalue was considered significant as the following:

- Probability (P-value)

- P-value <0.05 was considered significant.

- P-value <0.001 was considered as highly significant.

- P-value >0.05 was considered insignificant.

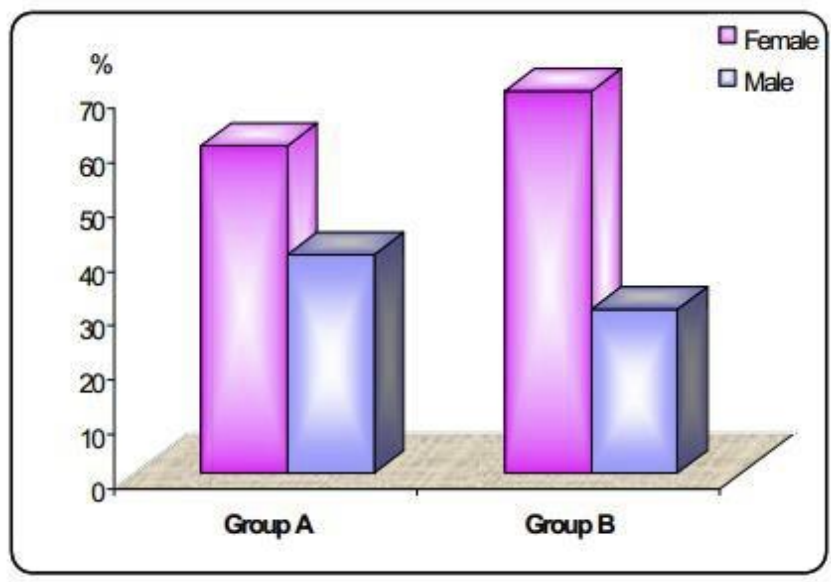

\section{RESULTS}

In group (A) there were twelve females and eight male patients, while in group (B) there were fourteen females and six male patients.

Figure (9): The percent of males and females in the two groups

The age of patients in group (A) was ranging from 30 to 65 years with amean age of $47.8 \pm 11.46$ years. While in group (B) the age of the patients was ranging from 32 to 70 years with a mean age of 48.9 \pm 10.67 years. The ranges of age of both groups are nearly close to each other and thereis no significant difference between the two groups. In group (A) there were two patients having diabetes mellitus, while in group (B) there werethree diabetic patients all of them was type II DM and they were on insulin treatment. There were seven patients in group (A) having hypertension while in group (B) there were eight patients having hypertension. Their blood pressure was controlled prior to surgery (table $\mathbf{1}$ ).

Table (1): Comparison between patient's criteria and co-morbidities of group (A) and group (B)

\begin{tabular}{|l|c|c|c|}
\hline & Group (A) & Group (B) & P Value \\
\hline Age (years) & $47.8 \pm 11.46$ & $48.9 \pm 10.67$ & 0.755 \\
\hline Sex (M:F) & $12: 8$ & $14: 6$ & 0.507 \\
\hline D.M. & 2 & 3 & 0.633 \\
\hline Hypertensio & 7 & 8 & 0.744 \\
\hline
\end{tabular}

Regarding abdominal ultrasound findings in group (A), thickened gall bladder wall was present in 13 cases, distended gall bladder in 17 cases and pericholecystic fluid collection was found in 3 cases. While abdominal ultrasound findings in group (B) were thickened gallbladder 
wall in 12 cases, distended gallbladder in 14 cases and peri-cholecystic fluid collection was found in 2 cases with no significant difference between both groups.

Table (2): comparison between laboratory Investigations and U/Sfindings in group (A) and group (B)

\begin{tabular}{|l|c|c|c|c|c|}
\hline & \multicolumn{2}{|c|}{ Group (A) } & \multicolumn{2}{|c|}{ Group (B) } & P value \\
\cline { 2 - 5 } & Num & $\%$ & Num & $\%$ & \\
\hline WBC & 13 & 65 & 10 & 50 & 0.337 \\
\hline $\begin{array}{l}\text { Thick GB } \\
\text { wall }\end{array}$ & 13 & 65 & 12 & 60 & 0.744 \\
\hline Distended GB & 17 & 85 & 14 & 70 & 0.256 \\
\hline $\begin{array}{l}\text { Peri- } \\
\text { cholecystic } \\
\text { Collection }\end{array}$ & 3 & 15 & 2 & 10 & 0.633 \\
\hline
\end{tabular}

As regard intraoperative modifications in group (A), gallbladder decompression was done in 14 cases and widening of epigastric port during extraction of the gallbladder was performed in 3 cases. For modifications in group (B), gall bladder decompression was done in 4 cases and widening of epigastric port during extraction of the gallbladder was performed in 2 cases.

The correlation between the two groups showed that there is statistically significant difference in favor of group (B) as regard gallbladder decompression and the difference is not significant as regard widening of epigastric port (table 3).

Table (3): intraoperative modifications in group (A) and group (B)

\begin{tabular}{|l|c|c|c|c|c|}
\hline \multirow{2}{*}{} & \multicolumn{2}{|c|}{ Group (A) } & \multicolumn{2}{c|}{ Group (B) } & \multirow{2}{*}{ P } \\
\cline { 2 - 5 } & Number & $\%$ & Number & $\%$ & \\
\hline Conversion & 3 & 15 & 4 & 20 & 0.677 \\
\hline GB & 14 & 70 & 4 & 20 & 0.001 \\
\hline $\begin{array}{l}\text { Widening of } \\
\text { epigastric }\end{array}$ & 3 & 15 & 2 & 10 & 0.633 \\
\hline
\end{tabular}

Intra-operative bleeding occurred once in group (A) and didn't occur in group (B) and it was due to avulsion of the cystic artery due to its difficult dissection. Conversion to open cholecystectomy with ligation of the bleeding vessel was done after a failed trial of controlling the artery during laparoscopy.

Postoperative bile leak occurred once in group (A) and it was due to slipped clips on the cystic duct which was treated by endoscopic retrograde cholangiography (ERCP) and stent placement. While postoperative jaundice occurred once in group (B) due to missed stone in the common bile duct, which was treated by ERCP and stone extraction.

Postoperative subhepatic collection occurred once in group (A) and it was treated with ultrasound guided pigtail insertion while postoperative collection occurred in two cases in group (B) and it was treated with pigtail insertion as well.

There were two cases of wound infection in group (A) at the epigastric wound. While there were three cases of wound infection in group (B). Two of them were at the epigastric wound and the other one was in the umbilical wound.

Postoperative complications occurred in 4 cases of group (A) while postoperative complications occurred in 6 cases of group (B) (table 4).

Table (4): Intraoperative and postoperative complications in group (A) and group (B)

\begin{tabular}{|c|c|c|c|c|c|}
\hline & \multicolumn{2}{|c|}{ Group (A) } & \multicolumn{2}{c|}{ Group (B) } & \multirow{2}{*}{ P value } \\
\cline { 2 - 5 } & Number & $\%$ & Number & $\%$ & \\
\hline Bleeding & 1 & 5 & 0 & 0 & 0.311 \\
\hline Wound infection & 2 & 10 & 3 & 15 & 0.633 \\
\hline Bile leak & 1 & 5 & 0 & 0 & 0.311 \\
\hline Collection & 1 & 5 & 2 & 10 & 0.548 \\
\hline Jaundice & 0 & 0 & 1 & 5 & 0.311 \\
\hline Postoperative & 4 & 20 & 6 & 30 & 0.633 \\
\hline
\end{tabular}

Total hospital stay in group (A) ranged from 3.5 to 6 days with a mean of $4.8 \pm 0.91$ days. While total hospital stay in group (B) ranged from 7 to 12 days with a mean of $9.2 \pm 1.61$ days. The correlation between the two groups showed that there is statistically significant difference in favor of group (A) (table 5).

Table (5): Total hospital stay in group (A) \& group (B).

\begin{tabular}{|l|c|l|l|}
\hline & \multicolumn{2}{|c|}{ Hospital stay } & \multirow{2}{*}{ P-value } \\
\cline { 2 - 3 } & Range & Mean \pm SD & \\
\hline Group A & $3.5-6$ & $4.80 \pm 0.91$ & \\
\hline Group B & $7-12$ & $9.20 \pm 1.61$ & $<0.001^{*}$ \\
\hline
\end{tabular}

\section{DISCUSSION}

In this study the male to female ratio in the early group was $8: 12$, while the male to female ratio in the delayed group was 6:14 and according to Sushant et al. ${ }^{(7)}$ the male to female ratio in the early group was $4: 26$, while the male to female ratio in the delayed group was 2:28.

In this study the range of age of patients with acute cholecystitis in the early group was 30 to 65 years with a mean age of $47 \pm 11.46$ years, and the range of age of patients with acute cholecystitis in the delayed group was 32 to 70 with a mean age of 48.9 \pm 10.67 years.

According to Eldar et al. ${ }^{(8)}$ the range of the age of patients with acute cholecystitis going to laparoscopic cholecystectomy was 18 to 92years with a mean of $62 \pm 15$ years. While Greenwald et $\boldsymbol{a l} .{ }^{(9)}$ reportedin their study that the mean of age of patients with acute cholecystitis undergoing laparoscopic cholecystectomy was $49.6 \pm 17.3$ years . 
The extreme of age of patients in the study of Eldar et $\boldsymbol{a l} .{ }^{(\mathbf{8})}$ may explain the higher rate of conversion to open cholecystectomy which was $24 \%$. While according to Greenwald $\boldsymbol{e t}$ al. ${ }^{(9)}$ the mean of age ofpatients was 49.6 years which is close to our mean of age of patients thatis why the rate of conversion to open cholecystectomy in Greenwald $\boldsymbol{e t}$ al. ${ }^{(9)}$ was $13 \%$. While the rate of conversion in our study was $17 \%$ (3 casesin the early group out of 20 patients and 4 cases in the delayed group outof 20 patients).

In this study the duration of acute symptoms in the early group ranged from 16 to 54 hours with mean of $35.6 \pm 11.17$ hours and the range ofduration of acute symptoms in the delayed group was 12 to 60 hours with mean of $36.6 \pm$ 14.38 hours.

According to Kolla et $\boldsymbol{a l}^{\left({ }^{(10)}\right.}$ the range of duration of acute symptoms in early group was $35.1 \pm 19.1$ hours and the range of duration of acute symptoms in delayed group was $36.1 \pm 24.7$ hours.

Ultrasound is usually the initial screening examination for biliarycolic, and is also sensitive for the detection of acute cholecystitis and gall bladder stones. It is widely available and relatively inexpensive.Ultrasound is extremely sensitive for the detection of gall stones, gallbladder wall thickening and pericholecystic fluid collection and permits anassessment of the location patient's pain in relation to the gall bladder ${ }^{(11)}$.

In this study, abdominal ultrasound findings in the early group werethickened gall bladder wall in 13 patients out of 20 patients $(65 \%)$ andthickened gall bladder wall in 12 patients out of $20(60 \%)$ patients in thedelayed group. Distended gall bladder was found in 17 cases in the earlygroup (85\%) and 14 cases in the delayed group (70\%) also pericholecystic collection was found in 3 cases in the early group (15\%) and pericholecystic collection was found in 2 cases $(10 \%)$ only in the delayedgroup.

According to Kolla et al. ${ }^{(\mathbf{1 0})}$ abdominal ultrasound findings in theearly group were thickened gall bladder wall in 12 patients $(60 \%)$ and thickened gall bladder wall in the delayed group was found in 11 patients $(55 \%)$. Distended gall bladder was found in 17 cases in the early group (85\%) and 15 cases in the delayed group (75\%) also pericholecystic collection was found in 3 cases in the early group (15\%) and the same in the delayed group.

In the current study the operative time in the early group was ranged from 85 to 140 minutes with a mean of $108.9 \pm 14.75$ minutes and the operative time in the delayed group was ranged from 65 to 106 minutes with a mean of $86.3 \pm 12.4$ minutes. The relatively longer operative time in the early group could be explained by time taken for dissection of adhesions, difficulty of grasping the gall bladder and some modifications as aspiration of the gallbladder.

According to Sushant $\boldsymbol{e t} \boldsymbol{a l}^{(7)}$ the mean operative time in the early group was 65.78 minutes and the mean operative time in the delayed group was 56.83 minutes, according to Kolla et al. ${ }^{(\mathbf{1 0 )}}$ the mean operative time in the early group was $104.3 \pm 44$ minutes and the mean operative time in the delayed group was $93 \pm 45$ minutes.

In this study the conversion rate to open cholecystectomy in the earlygroup was 15\% (3 cases due to difficulty of dissection in Calot's triangle and intraoperative bleeding). And the rate of conversion to open cholecystectomy in the delayed group was $20 \%$ (4 cases due to difficult dissection of Calot's triangle due to presence of dense adhesions obscuringthe normal anatomy).

According to Gutt et al. ${ }^{(12)}$ the conversion rate to open cholecystectomy was $9.9 \%$ in the early group while the rate of conversionto open cholecystectomy was $11.9 \%$ in the delayed group. On the otherhand, the rate of conversion to open cholecystectomy according to Kolla $\boldsymbol{e t} \boldsymbol{a l}{ }^{(\mathbf{1 0 )}}$ was $25 \%$ in both early and delayed group.

The pathophysiological basis for these results lies in understanding the progression of the acute inflammatory process. Early in the course of acute cholecystitis, the inflamed, edematous tissues are often helpful in delineating tissue planes. As inflammatory process continues these normal tissue planes are replaced by fibrotic adhesions that make dissection difficult ${ }^{(9)}$.

In this study gall bladder decompression was indicated in 14 cases inthe early group (70\%) and 4 cases in the delayed group (20\%), According to Sushant $\boldsymbol{e t} \boldsymbol{a l} .{ }^{(7)}$ gall bladder decompression was needed in 15 casesin the early group (50\%) and in 3 cases in the delayed group (10\%).

Postoperative wound infection in this study has occurred in 2 casesin the early group (10\%) while it has occurred in 3 cases in the delayedgroup (15\%). According to Kolla et al. ${ }^{(\mathbf{1 0})}$ wound infection has occurredin $5 \%$ of cases only in the earlygroup and in $10 \%$ of cases in the delayed group.

In this study postoperative bile leak has been noticed in one case in theearly group (5\%) due to slipped clips which was treated with ERCP andstenting and postoperative bile leak has not been noticed in the delayedgroup. According to Kolla et al. ${ }^{(\mathbf{1 0})}$ postoperative bile leak has beennoticed in 5\% of cases in the early group with no bile leak in the delayedgroup.

In the current study postoperative collection has been found in one case (5\%) in the early group and in two cases $(10 \%)$ in the delayed group, which were subhepatic and were detected by ultrasound and were treatedby pig tail insertion. According to Gutt et al. ${ }^{(\mathbf{1 2})}$ postoperative collectionhas been found in $3 \%$ of cases 
in the early group and $8 \%$ of cases in thedelayed group.

In this study postoperative jaundice has occurred in no cases in theearly group and has occurred in one case $(5 \%)$ in the delayed group due tomissed stone in the common bile duct and treated by endoscopic retrograde cholangiopancreatography and stone extraction. According to De Mestral et al. ${ }^{(\mathbf{1 4})}$ postoperative jaundice has been occurred in $3.6 \%$ of thedelayed group and it has been occurred in $1 \%$ of the early group.

In this study the total hospital stay in the early group ranged from 3.5to 6 days with a mean of $4.8 \pm$ 0.91 days and the total hospital stay in thedelayed group ranged from 7 to 12 days with a mean of $9.2 \pm$ 1.61 days. According to Gutt et al $^{(\mathbf{1 2})}$ the total hospital stay in the early groupranged from 4 to 6 days with a mean of 5.4 days and the total hospital stayin the delayed group ranged from 7 to 12 days with a mean of 10.03 days.

There is close correlation between our study and Gutt et $\boldsymbol{a l} .^{(12)}$ also thetotal hospital stay in the delayed group was double that in the early group. So, early laparoscopic cholecystectomy is more economic.

According to Kolla et al. ${ }^{(\mathbf{1 0 )}}$ the mean of total hospital stay in the early group was $4.1 \pm 8.6$ days and the mean of total hospital stay in the delayed group was $10.1 \pm 6$.1days. There was significant decrease in hospital stay in cases having earlylaparoscopic cholecystectomy when compared to those undergoing delayed laparoscopic cholecystectomy. This result is in harmony with similar several studies ${ }^{(\mathbf{1 0})}$.

\section{CONCLUSION}

Early laparoscopic cholecystectomy for patients with acute cholecystitis has both medical and socioeconomic benefits and it is the preferred approach in comparison to delayed approach.

\section{REFERENCES}

1. Lubasch A, Lode H (2000): Antibiotic therapy in cholecystitis, cholangitis and pancreatitis. Internist, 41:168-174.
2. Saber A, Hokkam EN (2014): Operative outcome and patient satisfaction in earlyand delayed laparoscopic cholecystectomy for acute cholecystitis. Minim Invasive Surg., 2014:162643. Livingston EH, Rege RV (2004): A nationwide study of conversion fromlaparoscopic to open cholecystectomy. Am J Surg., 188(3):205 -11.

3. Gurusamy KS, Samraj K (2006): Early versus delayed laparoscopic cholecystectomy for acute cholecystitis. Cochrane Database Syst Rev., 4:CD005440-CD005440.

4. Schirmer BD, Winters KL, Edlich RF (2005): Cholelithiasis and cholecystitis. J Long Term Eff Med Implants, 15:329-338.

5. Gurusamy K, Samraj K, Gluud C (2010): Metaanalysis of randomized controlled trials on the safety and effectiveness of early versus delayed laparoscopic cholecystectomy for acute cholecystitis. Br J Surg., 97:141-50.

6. Sushant V, Agarwal PN, Bali RS and Singh R (2013): Early versus delayed cholecystectomy for acute cholecystitis. Minimally Invasive Surgery, 13:1-3.

7. Eldar S, Eitan A, Bickel A, Sabo E, Cohen A, Abrahamson J and Matter I (1999): The impact of patient delay and physician delay on the outcome of laparoscopic cholecystectomy for acute cholecystitis. Am J Surg., 178: 303-307.

8. Greenwald JA, McMullen F, Coppa GF and Newman RM (2000): Standardization of surgeon controlled variables. Impact on outcome in patients with acute cholecystitis. Ann Surg., 231:339 -344.

9. Kolla SB, Aggarwal S and Kumar A (2004): Early versus delayed laparoscopic cholecystectomy for acute cholecystitis: a prospective randomized trial. Surg Endosc., 18:1323-1327.

10. Hirota M, Takada T, Kawarada Y et al. (2007): Diagnostic criteria and severity assessment of acute cholecystitis: Tokyo guidelines. J Hepatobiliary Pancreat Surg., 14:78-82.

11. Gutt CN, Encke J, Harnoss JC and Weigand K (2013): Acute cholecystitis early versus delayed cholecystectomy.Ann Surg., 258(3):385-93.

De Mestral CH, Rotstein OD and Laupacis A (2013): Comparative operative outcomes of early and delayed cholecystectomy for acute cholecystitis. Ann Surg., 259:10-15. 